\title{
Role of Knowledge Sharing in the Learning Process
}

\author{
Shaheen Majid, Panchapakesan Kumari Chitra \\ Nanyang Technological University, Singapore
}

\begin{abstract}
Knowledge sharing among peers plays an important role in students' learning process. The purpose of this study was to investigate students' attitude towards knowledge sharing with their class fellows, frequency and type of knowledge shared, preferred communication channels, and the factors likely to motivate or inhibit knowledge sharing. A pretested questionnaire was used for data collection and 226 junior college students participated in this study. It was found that the top three sources for seeking study-related information were the Internet, teachers, and classmates. The primary motives of sharing knowledge were to improve understanding of the concepts discussed in the class and to build relationships with classmates. For group assignments, more knowledge sharing occurred within the group members than with other groups. The major barriers to knowledge sharing were the lack of time, lack of a sharing culture, and inadequate depth in relationships. This paper suggests certain measures to encourage knowledge sharing among students.
\end{abstract}

\section{Introduction}

In recent years academic institutions are using different learning approaches to enhance students' learning experience. Collaborative learning is one of the established, popular and effective learning approaches. However, the success of this approach largely depends on students' attitude and behavior towards information and knowledge sharing with their peers. Some examples of collaborative academic activities, needing active knowledge sharing, are team projects, group presentations, in-class and online discussions, and collective problem solving. Proper integration of these activities into the instructional design could make learning more interactive and engaging. Many studies suggest that how collaborative learning, involving active knowledge sharing, brings many benefits to students such as better academic achievements, improved communication and interpersonal skills, appreciation for diverse ideas and viewpoints, positive inter-dependence, and a sense of satisfaction for contributing towards learning of others $[1,2,3]$. Students with a positive attitude towards knowledge sharing are also likely to carry this behavior to their workplace, thus contributing to their organizational success.

During the last two decades, the discipline of knowledge management is gaining popularity. As a result, academics and researchers are taking keen interest in different aspects of knowledge management, particularly in information and knowledge sharing among different categories of individuals. A considerable number of such studies have identified a wide variety of barriers to knowledge sharing in different types of organizations $[4,5,6]$. Many of these studies have also indicated that the major barrier to sharing is staffs' mind-set and unwillingness to share their knowledge due to a multitude of reasons.

Until recently, a majority of the studies on knowledge sharing were mainly focusing on corporate and public organizations. However, it was realized that it is equally important to understand knowledge sharing behavior of students as they will be part of the future workforce. Yuen and Majid [7] found that undergraduate students in Singapore possessed a positive attitude towards knowledge sharing and perceived it important for effective learning. However, they also reported that students were less inclined to share for those academic activities that were to be graded. Two major barriers inhibiting students from sharing their information and knowledge with classmates were lack of depth in relationship and the fear that other students will outperform them. Chen et al. [8] also reported that academic competition was associated with decreased knowledge sharing while trust, teamwork and instructors' positive attitude resulted in more knowledge sharing. Zaqout \& Abbas [9] investigated the factors stimulating tacit and explicit knowledge sharing among graduate students. They found a positive effect of trust, social networks and the use of ICT on knowledge sharing by students. Wei et al. [10] studied knowledge sharing behavior of 423 undergraduate students in Malaysia and reported that structured group activities were likely to encourage knowledge sharing among students. They also argued that academics can promote knowledge sharing by putting more emphasis on collaborative learning. Based 
on their study findings, they suggested that the management of public and private universities should take appropriate measures to encourage knowledge sharing among the students and, at the same time, make concerted efforts to reduce barriers to knowledge sharing.

In spite of students' positive attitude towards knowledge sharing, several studies have also pointed out certain barriers to knowledge sharing. Two major barrier reported by Majid and Wey [1]) were competition among students to outperform their classmates and the lack of depth in relationship. They suggested that academic institutions should reconsider their student assessment policies and procedures to make them less competitive and threatening. Ong et al. [11] found that lack of selfconfidence, self-centredness and certain social attributes can cause barriers to knowledge sharing. Another study showed that the three major factors inhibiting knowledge sharing among Jordanian university students were lack of time, lack of depth in relationship and academic competition [12]. Chiu [13] also claimed that students were less likely to share as knowledge is considered critical to their academic performance. The major barriers to knowledge sharing reported by Yaghi et al. [14] were lack of a sharing culture, lack of interaction opportunities, and students' believe that 'knowledge is power' and it cannot be shared with others.

As information and knowledge sharing is considered an essential element of the learning process, it is highly desirable that educators and other academic stakeholders should adequately understand the perceptions and knowledge sharing behavior of students and the barriers encountered by them. A majority of the previous studies on information and knowledge sharing have been undertaken in corporate settings and very little is known about knowledge sharing practices of students. Although some recent studies have investigated the information and knowledge sharing in academic settings, their focus was predominately on undergraduate and graduate students. There is a need to further expand the scope of such studies to pre-university academic institutions as students in this age group are likely to start maturing their knowledge sharing habits which they are likely to carry to universities or even to their workplaces.

The main objective of this study was to investigate the information and knowledge sharing behavior of pre-university students in Singapore. Some areas covered by this study were: perceptions and attitudes related to knowledge sharing, frequency and type of knowledge shared, preferred communication channels, and the factors likely to motivate or inhibit knowledge sharing. The findings of this study are expected to help teachers and education planners to adequately understand the knowledge sharing behavior of students, motivating and inhibiting factors, and the communication channels used by students. This may also help them to make necessary changes to the curriculum and their teaching methods.

\section{Method}

A questionnaire was used to collect data from 12 junior colleges from Singapore. The questionnaire was consisted of five sections and the first section of the questionnaire collected demographic information of the respondents. The next section gathered students' perceptions of information and knowledge sharing, sources used for seeking study-related information, and materials shared by them with their peers. Section 3 of the questionnaire was on different communication channels used for knowledge sharing and students' perceptions of the effectiveness of these channels. The last two sections solicited information about the factors that are likely to motivate or inhibit information and knowledge sharing among students.

The questionnaire was pre-tested to identify any semantic or presentation errors. As a result of pretesting, certain difficult words were replaced with simple words and options for two questions were modified. The research instrument was reviewed and approved by the Institutional Review Board (IRB) of Nanyang Technological University, Singapore. A convenience sampling technique was used and data collection work was completed in May-June 2012. A total of 226 students from 12 junior colleges in Singapore participated in this study. Of these respondents, 127 (56.2\%) were female and 99 (43.8\%) male students.

\section{Results and discussion}

The following sections present findings related to different aspects of knowledge sharing among students including attitudes towards knowledge sharing, sources used for knowledge seeking, knowledge sharing for study-related purposes, and motivating and inhibiting factors for knowledge sharing.

\subsection{Preferred sources for study-related information needs}

The students were asked to indicate their preference for different sources for meeting their study-related information needs. The purpose was to determine to what extent classmates were considered important for seeking study-related information. A five-point Likert scale, with five being the 'most preferred' and one being the 'least 
preferred', was used for data collection. It was found that the top three most preferred information sources for seeking study-related information were the Internet/search engines (means core: 4.27), subject teachers (mean score: 3.96 ), and classmates (mean score: 3.46) (see Table 1). It was worth noting that library was ranked quite low for seeking study-related information. It appeared that, among other sources, classmates were considered important for seeking study-related information and knowledge.

Table 1: Preferred sources for seeking study-related information $(\mathrm{N}=226)$

\begin{tabular}{|l|c|c|}
\hline & $\begin{array}{c}\text { Mean } \\
(\mathbf{1} \sim \mathbf{5})\end{array}$ & SD \\
\hline Search engines & 4.27 & .96 \\
\hline Subject teachers & 3.96 & .87 \\
\hline Classmates or other students & 3.46 & .89 \\
\hline Library resources & 2.75 & 1.22 \\
\hline $\begin{array}{l}\text { Friends outside the educational } \\
\text { institution }\end{array}$ & 2.69 & 1.18 \\
\hline
\end{tabular}

\subsection{Knowledge sharing for study-related purposes}

The respondents were asked how often they share their knowledge with their classmates for different study-related purposes. The purpose was to identify academic activities needing more active knowledge sharing. It was found that mean scores for all the academic purposes were in a very narrow range of 3.69 to 3.72. It appeared that knowledge sharing was equally widespread for almost all academic activities (see table 2).
Table 2: Knowledge sharing for study-related purposes $(\mathrm{N}=226)$

\begin{tabular}{|l|c|c|}
\hline \multicolumn{1}{|c|}{ Purposes } & $\begin{array}{c}\text { Mean } \\
(\mathbf{1 ~ 5 )}\end{array}$ & SD \\
\hline $\begin{array}{l}\text { To discuss requirements of class } \\
\text { projects, term papers or assignments }\end{array}$ & 3.72 & .927 \\
\hline $\begin{array}{l}\text { To clarify or discuss examination- } \\
\text { related matters }\end{array}$ & 3.70 & 1.027 \\
\hline To solve study related problems & 3.70 & 1.027 \\
\hline $\begin{array}{l}\text { To clarify or discuss certain concepts } \\
\text { learnt in the class }\end{array}$ & 3.69 & 1.007 \\
\hline
\end{tabular}

\subsection{Knowledge sharing for assignments}

Some previous studies suggest that assignments are the most common academic task for which students share their ideas and knowledge with their peers $[1,7]$. The respondents of this study were also asked about the frequency of knowledge sharing with their classmates for two given scenarios, when assignments are to be graded and when no grades are involved. The purpose was to investigate if students' sharing behavior was different for these two situations.

It was found that, for both the scenarios, knowledge sharing was more common within the same group members (see Table 3). Knowledge sharing was also common when students were working on individual assignments but on the same topic. However, comparatively there was less knowledge sharing with students from other groups or when different topics were assigned for individual assignments.

Table 3: Knowledge sharing for assignments $(\mathrm{N}=226)$

\begin{tabular}{|l|c|c|c|c|}
\hline \multicolumn{1}{|c|}{ Scenarios } & \multicolumn{2}{c|}{$\begin{array}{c}\text { Assignments to be } \\
\text { Graded }\end{array}$} & \multicolumn{2}{c|}{$\begin{array}{c}\text { Assignment NOT to } \\
\text { be Graded }\end{array}$} \\
\cline { 2 - 5 } & $\begin{array}{c}\text { Mean } \\
(\mathbf{1} \text {-5) }\end{array}$ & $\begin{array}{c}\text { Std. } \\
\text { Deviation }\end{array}$ & $\begin{array}{c}\text { Mean } \\
(\mathbf{1} \text { 5) }\end{array}$ & $\begin{array}{c}\text { Std. } \\
\text { Deviation }\end{array}$ \\
\hline $\begin{array}{l}\text { While doing group assignments (within their } \\
\text { own group) }\end{array}$ & 3.52 & 1.14 & 4.04 & .89 \\
\hline $\begin{array}{l}\text { While doing group assignments (with students } \\
\text { from other groups) }\end{array}$ & 3.10 & 1.10 & 3.23 & 1.14 \\
\hline $\begin{array}{l}\text { While doing individual assignments (same } \\
\text { topic for all students) }\end{array}$ & 3.45 & 1.26 & 3.75 & 1.05 \\
\hline $\begin{array}{l}\text { While doing individual assignments (different } \\
\text { topics) }\end{array}$ & 3.04 & 1.10 & 3.19 & .97 \\
\hline
\end{tabular}


It appeared that group assignments encouraged students to share knowledge, at least within their own groups, as all group members were expected to get the same reward or grade. Similarly, more sharing happened as group members need to discuss scope and coverage of their project, how to collect the needed information, how to present the compiled information, and how to improve the overall quality of their project. Knowledge sharing with students from other groups was low probably because of competition to get better grades. Similarly, there was only limited knowledge sharing while working on different individual topics.

\subsection{Types of materials shared}

The participating students were asked about their sharing frequency of different information and knowledge materials, using a 5-point Likert scale, where 5 represented the most frequently and 1 the least frequently. It was found that 'class notes/ hand outs' was the most frequently shared material with a mean score of 3.82 (see Table 4). As class notes/hand outs are given out by teachers, there sharing is less likely to give any edge to the receiving students. Rather the students might be thinking that by sharing these materials with classmates, who have missed certain classes, they can either strengthen their existing relationships or develop new friendships.

Table 4: Sharing of information materials

\begin{tabular}{|l|c|c|}
\hline \multicolumn{1}{|c|}{ Material Type } & $\begin{array}{c}\text { Mean } \\
(\mathbf{1} \text {-5) }\end{array}$ & SD \\
\hline Class notes/hand outs & 3.82 & 1.02 \\
\hline Previous assignments/term papers & 3.23 & 1.09 \\
\hline Previous exam papers & 3.05 & 1.18 \\
\hline Photocopies of articles & 2.96 & 1.16 \\
\hline Class presentation slides & 2.87 & 1.21 \\
\hline URLs of useful websites & 2.74 & 1.23 \\
\hline $\begin{array}{l}\text { Books/photocopies of book } \\
\text { chapters }\end{array}$ & 2.68 & 1.08 \\
\hline
\end{tabular}

The next three materials shared by the students were 'previous assignments/term papers' (mean score: 3.23), 'previous exam papers' (mean score: 3.05) and 'photocopies of articles' (mean score: 2.96). However, it was worth noting that mean scores of these materials were not very high, indicating only moderate sharing of these items. The least shared information materials were books and book chapters (mean score 2.68) and URLs of useful websites (mean score: 2.74 ). On the whole, it appeared that the students were basically sharing those materials that were also accessible to other students. However, there was less sharing of those materials that were individually collected by the students.

\subsection{Attitude towards knowledge sharing}

A set of statements was used to obtain opinions of the students about the different aspects of knowledge sharing. An agreement/disagreement scale was used for capturing their responses. An overwhelming majority $(86.3 \%)$ of the students either 'agreed' or 'strongly agreed' with the statement that with proper awareness and motivation, a positive attitude towards knowledge sharing can be developed (see Table 5).

Two other statements which were 'agreed' or 'strongly agreed' by nearly $70 \%$ of the respondents were "a person's knowledge sharing behaviour during study years is likely to continue at his/her workplace" and that "too much emphasis on grades discourages students from sharing their knowledge with classmates". Several previous studies have also reported that an over-emphasis on academic performance is likely to reduce knowledge sharing among students $[7,8,12,13]$.

On the other hand, $46.6 \%$ of the respondents either disagreed or strongly disagreed with the suggestion that knowledge sharing is a type of plagiarism. It indicated that the students were aware of the differences between knowledge sharing and unethical use of information. On the whole, it appeared that the students had a positive attitude towards knowledge sharing and were aware of its importance during studies and at the workplace.

\subsection{Preferred channels for knowledge sharing}

The participating students were asked to indicate their use frequency of various communication channels for sharing knowledge with their peers. As shown in Table 6, face-to-face interaction was the most frequently used method for knowledge sharing (mean 4.14), probably because of its immediacy, ability to capture non-verbal clues, and seek clarifications. Some previous studies have also revealed that face-to-face was the most popular channel for knowledge sharing $[1,7,12]$.

The Small Messaging Service (SMS) was ranked at the second position (mean score 4.03), probably because of its easy accessibility and convenient use. The advantage of SMS is that students usually cannot answer telephone calls while attending classes or busy in other activities. However, they can check their messages and reply at an appropriate time. 
Table 5: Attitude towards knowledge sharing

\begin{tabular}{|l|c|c|c|c|c|}
\hline \multicolumn{1}{|c|}{ Statements } & \multicolumn{4}{c|}{ Percentage of Responses (N=226) } \\
\cline { 2 - 5 } & SD & D & N & A & SA \\
\hline $\begin{array}{l}\text { With proper awareness and motivation, it is possible to } \\
\text { develop a positive attitude towards knowledge sharing. }\end{array}$ & $0.9 \%$ & $0 \%$ & $12.8 \%$ & $46.0 \%$ & $40.3 \%$ \\
\hline $\begin{array}{l}\text { A person's knowledge sharing behaviour during study } \\
\text { years is likely to continue at his/her workplace. }\end{array}$ & $3.5 \%$ & $1.8 \%$ & $20.3 \%$ & $52.7 \%$ & $21.7 \%$ \\
\hline $\begin{array}{l}\text { Too much emphasis on grads discourages students from } \\
\text { sharing their knowledge with classmates. }\end{array}$ & $0.9 \%$ & $9.7 \%$ & $19.9 \%$ & $41.6 \%$ & $27.9 \%$ \\
\hline $\begin{array}{l}\text { The belief of "knowledge is power" discourages } \\
\text { knowledge sharing. }\end{array}$ & $4.4 \%$ & $21.7 \%$ & $36.3 \%$ & $27.0 \%$ & $10.6 \%$ \\
\hline $\begin{array}{l}\text { Many students feel that knowledge sharing is a type of } \\
\text { plagiarism. }\end{array}$ & $12.0 \%$ & $34.6 \%$ & $28.8 \%$ & $19.5 \%$ & $5.3 \%$ \\
\hline
\end{tabular}

SD: Strongly disagree; D: Disagree; N: Neutral; A: Agree; SA: Strongly agree

It was interesting to note that online forums and discussion boards (mean score 2.47) were the least frequently used platforms by the students for studyrelated knowledge sharing. It was probably because most of the course-based discussion forums only provide access to topics suggested by instructors which may not be very attractive to students. Students were probably not allowed to discuss other study-related matters on these forums.

Table 6: Communication channels used for knowledge sharing $(\mathrm{N}=226)$

\begin{tabular}{|l|c|c|}
\hline Communication Channels & $\begin{array}{c}\text { Mean } \\
(\mathbf{1} \sim \mathbf{5})\end{array}$ & SD \\
\hline Face-to-face interaction & 4.14 & 1.06 \\
\hline Short Messaging Service (SMS) & 4.03 & 1.02 \\
\hline Telephone & 3.35 & 1.09 \\
\hline Email & 3.16 & 1.32 \\
\hline Online forums / discussion boards & 2.47 & 1.23 \\
\hline
\end{tabular}

To further explore, the respondents were asked about the effectiveness of different communication channels on a scale of one to five, with five denoting the 'most effective' and one the 'least effective'. The top three communication channels, based on their effectiveness, were face-to-face interaction, telephone and SMS (see Table 7). It was worth noting that although earlier telephone was placed at the 3rd position for its use, it was considered more effective for reliable communication. Even though physical gestures and facial expressions are not available in a standard telephone, attributes such as tone of voice, warmness and limited message distortion make it an effective communication tool. Once again, online forums appeared at the bottom of the list for their effectiveness in knowledge sharing.

Table 7: Perceived effectiveness of communication channels $(\mathrm{N}=226)$

\begin{tabular}{|l|c|c|}
\hline Communication Channels & Mean & SD \\
\hline Face-to-face interaction & 4.60 & .76 \\
\hline Telephone & 3.62 & .97 \\
\hline Short Messaging Service (SMS) & 3.37 & 1.04 \\
\hline Email & 3.16 & 1.20 \\
\hline Online forums / discussion boards & 2.71 & 1.17 \\
\hline
\end{tabular}

\subsection{Factors motivating knowledge sharing}

The respondents were asked what factors are likely to motivate them to share their knowledge with peers. As shown in Table 8, the top two motivating factors were to improve understanding of concepts discussed in the class (mean score: 3.80) and to develop relationship with other students (mean score: 3.75). The importance of social networking in knowledge sharing was also highlighted by Zaqout \& Abbas [9] and Wei et al. [10]. The next four motivating factors, with comparable mean scores, were the feeling of belongingness, to gain respect from classmates, selfsatisfaction, and the urge to help others. However, the respondents expressed the opinion that they do not share their knowledge either to obtain class participation marks or to impress their teachers. It indicates that the students were aware of the benefits of knowledge sharing in their learning process. 
Table 8: Factors motivating knowledge sharing $(\mathrm{N}=224)$

\begin{tabular}{|l|c|c|}
\hline \multicolumn{1}{|c|}{ Motivating Factors } & $\begin{array}{c}\text { Mean } \\
(\mathbf{1 ~ 5 )}\end{array}$ & SD \\
\hline $\begin{array}{l}\text { To improve understanding of } \\
\text { concepts learnt in the class through } \\
\text { sharing ideas with other students }\end{array}$ & 3.80 & .91 \\
\hline $\begin{array}{l}\text { To develop relationships with } \\
\text { other students }\end{array}$ & 3.75 & 1.01 \\
\hline $\begin{array}{l}\text { To feel belonged to and fit into a } \\
\text { group }\end{array}$ & 3.57 & .97 \\
\hline $\begin{array}{l}\text { To gain respect from others by } \\
\text { portraying image of a } \\
\text { knowledgeable person }\end{array}$ & 3.57 & 1.04 \\
\hline Self-satisfaction & 3.56 & .99 \\
\hline Out of altruism to help others & 3.55 & .90 \\
\hline $\begin{array}{l}\text { For rewards e.g. class or online } \\
\text { forum participation marks }\end{array}$ & 3.48 & 1.17 \\
\hline To impress teacher & 3.04 & 1.25 \\
\hline
\end{tabular}

\subsection{Factors inhibiting knowledge sharing}

One of the research objectives of this study was to identify the factors that might limit knowledge sharing among students. As shown in Table 9, the top three most likely inhibiting factors were lack of time (mean score 4.00), lack of knowledge sharing culture in the junior college (mean score 3.79), and lack of depth in relationship (mean score 3.76). Some previous studies [12, 14] have also reported these barriers to knowledge sharing. Although earlier in section 3.3 it was revealed that more knowledge sharing was likely for nongrading assignments, students here did not consider that 'fear that other students may outperform me in studies' was a major inhibiting factor for knowledge sharing. Two least likely inhibiting factors for knowledge sharing among students were 'do not know what to share' (mean score 3.15) and 'limited opportunities for face-toface interactions with other students' (mean score 3.07). It appeared that students were satisfied with the opportunities available to them for face-to-face interaction, resulting in more knowledge sharing. This finding is in line with a previous finding (section 3.6) where face-to-face interaction appeared to be the most preferred channel for knowledge sharing.
Table 9: Factors inhibiting knowledge sharing $(\mathrm{N}=224)$

\begin{tabular}{|l|c|c|}
\hline \multicolumn{1}{|c|}{ Inhibiting Factors } & $\begin{array}{c}\text { Mean } \\
(\mathbf{1} \text {-5) }\end{array}$ & SD \\
\hline Lack of time & 4.00 & 1.031 \\
\hline $\begin{array}{l}\text { Lack of knowledge sharing culture in } \\
\text { the college }\end{array}$ & 3.79 & .979 \\
\hline Lack of depth in relationship & 3.76 & .901 \\
\hline Fear of providing wrong information & 3.72 & .925 \\
\hline $\begin{array}{l}\text { Lack of initiatives to voluntarily } \\
\text { share information }\end{array}$ & 3.65 & .954 \\
\hline $\begin{array}{l}\text { Students only share with those who } \\
\text { share with them }\end{array}$ & 3.62 & 1.077 \\
\hline $\begin{array}{l}\text { Fear of being portrayed as "show- } \\
\text { off" }\end{array}$ & 3.61 & 1.143 \\
\hline $\begin{array}{l}\text { Fear that other students may } \\
\text { outperform me in studies }\end{array}$ & 3.49 & 1.220 \\
\hline $\begin{array}{l}\text { Fear that a clash of opinions may } \\
\text { spoil relationship }\end{array}$ & 3.37 & 1.101 \\
\hline $\begin{array}{l}\text { Lack of appreciation for knowledge } \\
\text { sharing }\end{array}$ & 3.37 & 1.171 \\
\hline Do not know what to share & 3.15 & 1.129 \\
\hline $\begin{array}{l}\text { Limited opportunities for face-to-face } \\
\text { interactions with other students }\end{array}$ & 3.07 & 1.118 \\
\hline
\end{tabular}

\section{Conclusion}

It was satisfying to note that the participants of this study were fully aware of the benefits of knowledge sharing and showed a positive attitude towards it. However, as also pointed out by several previous studies, academic competition among students was hindering knowledge sharing. Academic institutions need to think about alternative assessment methods to reduce direct competition among students. In addition, this study has also identified certain other barriers to knowledge sharing. It is, therefore, desirable that educators and education planners should take appropriate measures to minimize such barriers to knowledge sharing which in turn are likely to strengthen students' believe on the value of knowledge sharing. Once convinced, students are likely to take this positive attitude to their workplace and contribute to their organizational success. 


\section{References}

[1] Majid, S., \& Wey, S.M. (2009). Perceptions and kknowledge sharing practices of graduate students in Singapore. International Journal of Knowledge Management, 5(2): 21-32.

[2] So, H.J., \& Brush, A.T. (2008). Student perceptions of collaborative learning, social presence and satisfaction in a blended learning environment: Relationship and critical factors. Computer and Education, 51: 318-336.

[3] Bullard, L.G., \& Felder, R.M. (2007). A studentcentered approach to teaching materials and energy balances: Course delivery and assessment. Chemical Engineering Education, 41(3), 167-176.

[4] Sharma, B. P., Singh, M. D., \& Neha. (2012). Knowledge Sharing Barriers: An Approach of Interpretive Structural Modeling. IUP Journal of Knowledge Management, 10(3), 35-52.

[5] Lilleoere, A., \& Hansen, E. H. (2011). Knowledgesharing enablers and barriers in pharmaceutical research and development. Journal of Knowledge Management, 15(1), 53-70.

[6] Riege, A. (2005). Three-dozen knowledge-sharing barriers managers must consider. Journal of Knowledge Management 9(3): 18-35.

[7] Yuen, T.J. \& Majid, S. (2007) Knowledge Sharing Patterns of Undergraduate Students in Singapore. Library Review, 56(6): 485-494.

[8] Chen, J., Koch, M., Chung, M., \& Chu-Keong, L. (2007). Exploring contributory factors in student-tostudent knowledge sharing. Conference papers - National Communication Association.

[9] Zaqout, F., \& Abbas, M. (2012). Towards a model for understanding the influence of the factors that stimulate university students' engagement and performance in knowledge sharing. Library Review, 61(5), 345-361.

[10] Wei, C., Choy, C., Chew, G., \& Yen, Y. (2012). Knowledge sharing patterns of undergraduate students. Library Review, 61(5), 327-344.

[11] Ong, H., Yeap, P., Tan, S., \& Chong, L. (2011). Factors Influencing Knowledge Sharing among Undergraduate Students: A Malaysian Perspective. Industry and Higher Education, 25(2), 133-140.

[12] Hussein, A., \& Nassuora, A. (2011). Jordanian Student's Attitudes and Perceptions towards Knowledge Sharing in Institutions of Higher Education. International Journal of Academic Research, 3(4), 401-405.

[13] Chiu, S. (2010). Students' Knowledge Sources and Knowledge Sharing in the Design Studio--An Exploratory
Study. International Journal of Technology and Design Education, 20(1), 27-42.

[14] Yaghi, K., Barakat, S., Alfawaer, Z. M., Shkokani, M., \& Nassuora, A. (2011). Knowledge Sharing Degree among the Undergraduate Students: A Case Study at Applied Science Private University. International Journal of Academic Research, 3(1), 20-24. 